\title{
Engelli Bireylerde Tiyatro Aktivitesinin İletişim ve Etkileşim Becerileri Üzerine Etkilerinin İncelenmesi
}

Effects of Theatre Activity on Communication and Interaction Skills of People With Disabilities

Fatma GÜN ${ }^{1}$, Burcu Semin AKEL ${ }^{2}$

${ }^{1}$ Erg, Leksia Kişisel Gelişim ve Danışmanlık Merkezi, Ankara,

${ }^{2}$ Doç.Dr. Hacettepe Üniversitesi, Sağlık Bilimleri Fakültesi, Ergoterapi Bölümü, Ankara

\section{öz}

\begin{abstract}
Amaç: Çalışmamızda, tiyatro aktivitesinin oyuncuları aktive eden ve kendine güveni artıran yapısı göz önüne alınmıştır ve engelli bireyde tiyatro aktivitesinin iletişim ve etkileşim becerileri üzerindeki etkilerinin incelenmesi amaçlanmıştır. Gereç ve Yöntem: Çalışmaya daha önceden tiyatro eğitimi almamış, tiyatro çalışması için bir sanat atölyesine ilk defa başvurmuş, herhangi bir konuşma problemi ve ağır mental retardasyonu olmayan 7 kişi alındı. Çalışmada Insan Aktiviteleri Modeli kapsamında geliştirilen Iletiş̧im ve Etkileşim Becerileri Değerlendirmesi kullanıldı. Bu değerlendirmeye göre kişiler 60 dakika gözlemlendi ve gözleme göre Illetişim ve Etkileşim Becerileri Değerlendirmesi alt parametre (fiziksellik, bilgi alışverişi, ilişkiler) puanları verildi. Kişiler ısınma çalışmaları ve provalardan oluşan 12 seansa katıldı. Tiyatro seansların sonunda, iletişim ve etkileşime ait değişimleri saptamak için İletişim ve Etkileşim Becerileri Değerlendirmesi tekrar yapıldı. Sonuçlar: Beşi erkek $(\% 71,4)$, 2'si kadın $(\% 28,6)$ olan 7 bireyin ortalama

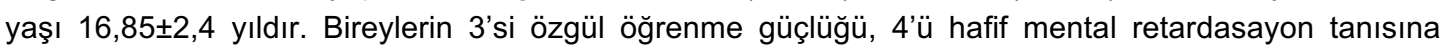
sahipti. Katılımcılar, ilk Illetişim ve Etkileşim Becerileri Değerlendirmesi değerlendirmesinden ortalama $46,42 \pm 12,75$ (ortanca=56) puan, tiyatro aktivitesinin ardından ortalama $64,14 \pm 8,35$ puan aldı. Katılımcıların iletişim ve etkileşim becerilerindeki fark istatiksel olarak anlamlı bulundu $(p=0,018)$.Tartışma: Tiyatronun iletişim etkileşim becerilerinde gelişme sağladığı görülmektedir. Yine de büyük örneklem gruplarıyla yapılacak kontrollü çalışmalar gerekmektedir.
\end{abstract}

Anahtar Kelimeler: Kişilerarası ilişkiler; İletişim; Rol oynama; Engelli bireyler

\section{ABSTRACT}

Purpose: In this study, the nature of theatre activity which activates the performers and increases selfconfidence was considered and it was aimed to investigate the effects of theatre activity on communication and interaction skills of individuals with disability. Material and Methods: Seven disabled people who had applied to join an art atelier and had never taken theater training before and did not have speech problems or severe mental retardation were included in the study. Assessment of Communication and Interaction Skills (ACIS) was used in the study. Individuals were observed for 60 minutes and then ACIS score for each parameter (physicality, information exchange, relations) was scored. The participants attended 12 sessions which consisted of theatre warm-up exercises and rehearsals. After theatre sessions, ACIS was applied again to evaluate changes in communication. Results: Five male (\%71.4), 2 female (\%28.6) totally 7 individuals had the mean age of $16.85 \pm 2.4$ years. 3 individuals had learning disability and 4 had mild mental retardation. The participants' scored an average of $46.42 \pm 12.75$ (median=56) at the first ACIS assessment, then scored $64.14 \pm 8.35$ after theatre activity. The improvement in the communication and interaction skills was statistically significant $(p=0.018)$. Conclusion: This study proved that the theatre activity improves communication and interaction skills. Nevertheless, further controlled studies with larger sample groups are needed.

Keywords: Interpersonal relations; Communication; Role playing; Disabled people 
İletişim ve etkileşim becerileri, bireylerin amaçlarını ve intiyaçlarını iletmek, başkaları ile fiziksel olarak ilişki kurmak, konuşmak, işbirliği yapmak ve kendini savunmak gibi toplumsal olarak kişilerle etkileşim kurmak için kullanılan gözlemlenebilir hedefe yönelik davranışlar olarak tanımlanır (Lexén ve Bejerholm, 2016). Bu beceriler, başkalarına ve/veya kişinin ve başkalarının ortak ilgi gösterdiği nesneler veya süreçlere yönelik eylemlerdir ve kendine bakım, iş/üretici ve serbest zaman aktivitelerinde performansın sağlanmasında önemlidir. $\mathrm{Bu}$ aktivitelerin çoğu kişinin yalnız olmadığı ortamlarda ve farklı kişilerle iletişim ve etkileşim halindeyken gerçekleşmektedir (Forsyth,, Kielhofner, Forsyth ve ark, 1998).

Engelli bireylerde sıklıkla iletişim ve etkileşim becerileri etkilenmektedir. İletişim kurmaya motive olmakta, iletişimi sürdürmede belli bir dikkat seviyesine ulaşmakta, interaktif çevre ile olan etkileşiminde ve çevreyi kendine göre kullanmakta, iletişimde kendine yöneltilen mesaja gerekli dönütü oluşturmakta, sözsüz iletişimde objeleri diğer kişiler ile ortak odak noktası olarak kullanmakta sorunlar yaşamaktadırlar (Perry, 2003). Geçtiğimiz yirmi yıl içerisinde önemli iletişim ihtiyaçlarına sahip bireylere fayda sağlayan değerlendirme ve müdahale konusunda gelişmeler sağlanmıştır. Bununla birlikte, engelli bireylerin karşılanmamış iletişim desteği intiyaçları vardır (Lexén ve ark, 2016).

Tiyatro, başka insanlarla çalışmak, hazırlanmak, kendini gerçekleştirmek, fikir alışverişinde bulunmak, meydan okumaya yanıt vermek, risk almak, provalara ve halka açık gösterilere katılmak ve karar vermek için fırsat sağlayan bir yapıya sahiptir (Hughes ve Wilson, 2004). Yapılan araştırmalarda tiyatro çalışmalarının, kişisel ve sosyal açıdan etkileri olduğu bulunmuştur. Katılımcılar tarafından en sık bildirilen etkiler kendine güvende, arkadaş edinme becerisinde, benlik algısında, başkasına yardımcı olma isteğinde, iletişim becerilerinde, konsantrasyon ve hayal gücünde artıştır. Ek olarak başkalarını anlama ve başkalarıyla beraber çalışabilme becerisinde gelişme, kendini daha iyi ifade edebilme, olumsuz ve uygunsuz davranışlardan kaçınma, başkalarının fikirlerine saygı duyma, zor deneyimlerle başa çıkmaya yönelik becerilerde gelişme olduğunu da belirtmişlerdir (Hughes ve ark, 2004; Catterall, Chapleau ve Iwanga, 1999). Bu bilgiler ışığında, tiyatro aktivitesinin kullanımı ile iletişim ve etkileşim becerilerinde problem yaşamakta olan engelli bireylerin iletişim ve etkileşim becerilerinin geliştirilmesinin mümkün olacağı düşünülmüştür (Hughes ve ark, 2004) ancak literatürde kanıt sağlayacak bir çalışmaya rastlanmamıştır.

Literatürde, sağlıklı bireylerin drama, tiyatro, müzik ve resim gibi sanatlarla ilgilenmeye başladığında iletişim ve etkileşim becerilerinin başlangıçtaki duruma göre arttığı gösterilmiştir (Johnston, 2012). Engelli bireylerin klinik ortam dışında kendine güvenli ve bağımsız bir yaşam sürdürebilmelerinin desteklenmesi için sanat aktivitelerine katılımlarının önemi vurgulanmıştır (Sandahl, 2005; Johnston, 2012). Ayrıca sahnelenmek üzere, profesyonel bir çalışma ile hazırlanan, kişilerin adeta bir üretici aktivite gibi algıladığı tiyatro aktivitelerinin, kişilerin yaşamlarını bağımsız olarak sürdürebilmek için intiyaç duyacakları sosyal ve kişisel becerileri önemli ölçüde geliştirebileceğinden bahsedilmektedir (Hughes ve ark, 2004). Bu yönüyle, profesyonel bir çalışmayla, klinik ortam dışında yürütülen tiyatro eğitimi, katılımcıların bağımsız yaşam becerilerini destekler niteliktedir.

Türkiye'de engelli birey sayısının toplam nüfusa oranı \%12 (Türkiye İstatistik Kurumu [TÜİK], 2002) olmasına rağmen, Çöl'ün (2015) yaptığı çalışmada ülkemiz şartlarında engelli bireyler için müzik/resim/el sanatları dışındaki, örneğin tiyatro gibi, yetenek gerektiren aktivitelere katılım imkanının az olduğu saptanmıştır. Engelli bireylerin kişisel, çevresel ve ailesel etmenlerden dolayı ev dışı fiziksel ve sosyal aktivitelere katılım düzeyleri oldukça düşüktür (Çöl, 2015).

Bu çalışmada engelli bireylerde tiyatro aktivitesinin iletişim ve etkileşim becerileri üzerine etkisinin değerlendirilmesi amaçlanmıştır.

\section{GEREÇ VE YÖNTEM}

Çalışmaya ilk defa bir sanat atölyesine başvurmuş ve daha önce herhangi bir tiyatro eğitimi almamış engelli bireylerin dahil edilmesi planlandı. Bireyleri dahil etmeme kriterleri konuşma apraksisi, dizartri, afazi gibi konuşma problemlerinin olması ve ağır mental retardasyonu olmaması olarak belirlendi. Tiyatro için başvuran bireylerde dahil etmeme kriterlerine uyan olmadığı için başvuran 10 birey çalışmaya alındı. Ardından çalışmaya katılan bireylerin bakım verenine çalışma anlatıldı ve imzalı onam formu alındı. Tiyatro çalışmaları boyunca çalışmanın içeriğini ve rol dağılımları sanat atölyesindeki engelli tiyatrosunda uzman kişiler tarafından belirlenmiştir ve tüm katılımcılar aktif rol almıştır. Çalışmanın ileri evrelerinde 3 kişi sağlık problemler nedeniyle çalışmadan ayrıldı. Devam eden kişilerin 3 tanesi özgül öğrenme güçlüğü 4 
tanesi hafif MR tanısına sahiptir. Düzenli devam eden 7 bireyle çalışma sonlandırıldı. Değerlendirme ölçekleri olarak demografik bilgi toplama anketi ile İletişim ve Etkileşim Becerileri Değerlendirmesi kullanıldı.

\section{Demografik Bilgi Toplama Anketi}

Tüm çocuklardan değerlendirmeye başlamadan önce aşağıdaki demografik bilgiler alınmıştır; çocuğun adı, yaşı, cinsiyeti, eğitim durumu, evde yaşayan birey sayısı, kardeş sayısı, hanedeki engelli sayısı, tiyatro geçmişi, aldığı tedaviler ve tanısı kaydedilmiştir.

Iletişim Ve Etkileşim Becerileri Değerlendirmesi İletişim ve Etkileşim Becerilerinin Değerlendirilmesi ilk defa 1989 yılında geliştirmiştir (Simon, 1989). Insan aktivite modelinde (MOHO) kavramsallaştırılan İletişim ve Etkileşim Becerileri Değerlendirmesi (Forsyth, Lai ve Kielhofner, 1999) kişinin iletişim ve etkileşim becerilerini değerlendirmek için tasarlanmış gözlemsel bir derecelendirme ölçeğidir. İletişim ve Etkileşim Becerileri Değerlendirmesi, iletişim becerilerinin işlevlerini etkileyen herhangi bir tanısı olan kişilerle birlikte kullanılmak üzere tasarlanmıştır. $\mathrm{Bu}$ değerlendirme, kişilerin bir aktivitede iletişim kurarken ve başkalarıyla etkileşim içerisindeyken gösterdikleri yetenek hakkında veri toplayan gözlemsel bir değerlendirmedir. Bir aktivite performansı sırasında sergilendiği şekliyle ve/veya kişinin parçası olduğu toplumsal bir grup içerisinde kullanıldığı şekliyle iletişim ve etkileşim becerileri hakkında bilgi sağlar. Performans becerilerini temsil eden davranışlar ya da eylem fiillerinden oluşan alt başlıklara sahiptir. Bu alt başlıklar, fiziksellik, bilgi alış-verişi ve ilişkiler adında 3 beceri grubunu oluşturur. Alt parametrelerinin detaylı açıklaması Ek1 de bulunmaktadır. Terapist, bir kişinin toplumsal bir duruma girdiğini gözledikten sonra her beceri alanı için puan verir. Sosyal durum, kişinin ve terapistin fikir birliğiyle belirlenir ve böylece kişi için anlamlı olur. Devam eden sosyal eylemi destekleyen bir beceri 4 derecelik bir skalada puanlandırılır; devam eden toplumsa eylemi destekliyorsa 4, şüpheli ise 3; devam eden toplumsal eylemi limitliyorsa 2; ve beceri kabul edilemez bir gecikmeye veya sosyal etkileşimde bozulmaya neden oluyorsa 1 olarak puanlanır. Terapist, kişiyi kendisiyle alakalı ve kendisi için anlamlı bir sosyal bağlamda gözlemledikten sonra kişiyi iletişim etkileşim becerileri alt başlıklarından her birinde değerlendirmek için İletişim ve Etkileşim Becerileri Değerlendirmesi kullanır. Eksik ya da bozulmuş iletişim ve etkileşim becerilerinin altında yatan nedenleri doğrudan saptamaz, yalnızca belirli bir becerinin var olup olmadığını ve süregelen sosyal eylemi nasıl etkilediğini gösterir. Hastalık / hastalığın iletişim ve etkileşim yetenekleri üzerindeki sonuçlarını ölçmek için kullanılmaya yöneliktir, bu nedenle değerlendirme teşhis konusuna bağlı değildir (Forsyth ve ark, 1999).

İletişim ve Etkileşim Becerileri Değerlendirmesi ilk olarak 02.01.2017 tarihinde bireylerin bulunduğu özel eğitim ve rehabilitasyon merkezinde gerçekleştirildi. Bireyler ilk prova sırasında 60 dakika gözlemlendi. Yapılan gözlemin sonucunda her bireye İletişim ve Etkileşim Becerileri Değerlendirmesi'nin alt başlıklarına göre araştırmacı tarafından puan verildi. Araştırmacı ardışık birkaç provaya daha katılıp gözlem puanlarından emin oldu. Sanat Atölyesi tarafından tiyatro eğitimi 12 hafta boyunca haftada 1 gün toplam 12 kez olmak üzere gerçekleşti.12 haftalık provaların ardından ikinci değerlendirme yapıldı.

\section{İstatistiksel Analiz}

Verilerin istatistiksel analizlerinde IBM SPSS 20 programı kullanıldı. Bireylerin sosyodemografik özellikleri cinsiyet, tanı, tiyatro geçmişi, yaş, eğitim durumu, evde yaşayan kişi sayısı, kardeş sayısı ve hanedeki engelli sayısı gibi tanımlayıcı verilerde uygunluğuna göre frekans veya ortalama \pm standart

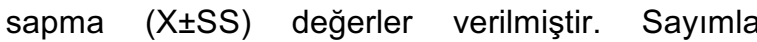
belirlenen değişkenler için yüzde (\%) değeri hesaplanmıştır. İletişim ve Etkileşim Becerilerinin Değerlendirmesi'nde çalışma öncesinde ve sonrasında elde edilen değerler Wilcoxon Eşleştirilmiş Test ile karşılaştırılmış ve anlamlılık değeri 0,05 olarak kabul edilmiştir.

\section{SONUÇLAR}

Çalışmaya 5’i erkek $(\% 71,4)$ 2'si kadın $(\% 28,6)$ olmak üzere toplam 7 birey dahil edilmiştir. Dahil edilen bireylerin ortalama yaşı $16,85 \pm 2,4$ yıl (minimum:13, maksimum:21) olarak kaydedilmiştir. Tablo 1'de bireylerin sosyodemografik özellikleri verilmiştir.

Katılımcıların İletişim ve Etkileşim Becerileri Değerlendirmesi'nin alt parametreleri olan Temas, bakışlar, yönelmeler, postür, telaffuz, kendini savunma, etkileşimi başlatma, etkileşimi sürdürme, duygulanımını ifade etme, sesini ayarlama, kendini ifade etme, odaklanma ve saygı duyma becerilerinde anlamlı bir fark bulunmuştur $(p<0,05)$. İletişim ve Etkleşim Becerileri Değerlendirmesi'nin tüm maddeleri hakkında ayrıntılı sonuç dökümü Tablo 2'de bulunmaktadır. 
Tablo 1. Katılımcıların Sosyodemografik Özellikleri $(n=7)$

\begin{tabular}{lll} 
Sosyodemografik Özellikler & $\mathbf{n}(\%)$ & \\
\hline Cinsiyet & $2(28,6)$ & \\
Kadın & $5(71,4)$ & \\
Erkek & $3(28,6)$ & \\
\hline Tanı & $4(58,1)$ & Minimum/maksimum \\
Özel öğrenme güçlüğü & $\mathbf{X}+\mathbf{S S}$ & $13 / 21$ \\
\hline Hafif MR & $16,85 \pm 2,41$ & $7 / 12$ \\
\hline Sosyademegrafik Özellikler & $10,14 \pm 1,57$ & $2 / 5$ \\
\hline Yaş & $3,71 \pm 0,95$ & $0 / 2$ \\
\hline Ĕ̆itim Durumu & $1,14 \pm 0,69$ & $0 / 1$ \\
\hline Evde yaşayan birey sayısı & $0,28 \pm 0,48$ & \\
\hline Kardeş sayısı & & \\
\hline Hanedeki engel sayısı & & \\
\hline
\end{tabular}

Tablo 2.Katılımcıların tedavi öncesi ve sonrası İletişim ve Etkileşim Becerileri Değerlendirmesi'nin karşılaştırılması

\begin{tabular}{|c|c|c|c|c|c|c|}
\hline & $\begin{array}{l}\text { Uygulama } \\
\text { Öncesi } \\
X \pm S S\end{array}$ & 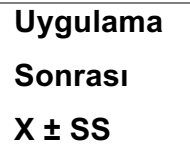 & $\begin{array}{l}\text { Uygulama } \\
\text { öncesi } \\
\text { Medyan }\end{array}$ & $\begin{array}{l}\text { Uygulama } \\
\text { sonrası } \\
\text { Medyan }\end{array}$ & $\mathbf{z}$ & $\mathbf{p}$ \\
\hline Fiziksellik & $13,85 \pm 4,56$ & $19,71 \pm 3,03$ & 13 & 21 & $-2,366$ & $0,018^{*}$ \\
\hline Temas & $2,28 \pm 0,75$ & $3,28 \pm 0,75$ & 2 & 3 & $-2,646$ & $0,008^{*}$ \\
\hline Bakış & $2,14 \pm 0,69$ & $3,00 \pm 0,00$ & 2 & 3 & $-2,121$ & $0,34^{*}$ \\
\hline Jestler & $2,14 \pm 6,9$ & $2,85 \pm 0,69$ & 2 & 3 & $-1,890$ & 0,059 \\
\hline Manevralar & $2,57 \pm 1,27$ & $3,42 \pm 0,78$ & 3 & 4 & $-1,890$ & 0,059 \\
\hline Yönelmeler & $2,42 \pm 0,78$ & $3,57 \pm 0,53$ & 2 & 4 & $-2,271$ & $0,023^{*}$ \\
\hline Postür & $2,28 \pm 0,95$ & $3,57 \pm 053$ & 2 & 4 & $-2,251$ & $0,024^{*}$ \\
\hline Bilgi Alışverişi & $19,42 \pm 5,53$ & $27,00 \pm 4,20$ & 17 & 28 & $-2,371$ & $0,018^{*}$ \\
\hline Telaffuz & $2,28 \pm 0,09$ & $3,00 \pm 0,81$ & 2 & 3 & $-2,236$ & $0,025^{\star}$ \\
\hline Kendini Savunma & $2,42 \pm 0,53$ & $3,28 \pm 0,48$ & 2 & 3 & $-2,449$ & $0,014^{*}$ \\
\hline Soru Sorma & $2,00 \pm 1,00$ & $2,71 \pm 0,75$ & 2 & 3 & $-1,890$ & 0,059 \\
\hline Etkileşimi Başlatmak & $1,28 \pm 0,48$ & $2,71 \pm 0,48$ & 1 & 3 & $-2,271$ & $0,023^{*}$ \\
\hline Duygulanımı İfade Etmek & $2,28 \pm 0,75$ & $2,85 \pm 0,69$ & 2 & 3 & $-2,000$ & $0,046^{*}$ \\
\hline Sesini Ayarlama & $2,28 \pm 1,11$ & $3,42 \pm 0,53$ & 2 & 3 & $-2,271$ & $0,023^{*}$ \\
\hline Paylaşmak & $2,28 \pm 0,75$ & $3,00 \pm 0,57$ & 2 & 3 & $-1,890$ & 0,059 \\
\hline Kendini İfade Etmek & $2,42 \pm 0,53$ & $3,00 \pm 0,57$ & 2 & 3 & $-2,000$ & $0,046^{*}$ \\
\hline Sürdürmek & $1,85 \pm 0,89$ & $2,71 \pm 0,48$ & 2 & 3 & $-2,121$ & $0,034^{*}$ \\
\hline İlişkiler & $12,85 \pm 3,23$ & $17,42 \pm 1,61$ & 13 & 18 & $-2,379$ & $0,017^{*}$ \\
\hline İşbirliği Yapma & $2,42 \pm 1,27$ & $3,14 \pm 0,69$ & 2 & 3 & $-1,890$ & 0,059 \\
\hline Uyumlu OIma & $3,42 \pm 0,53$ & $3,85 \pm 0,37$ & 3 & 4 & $-1,732$ & 0,083 \\
\hline Odaklanma & $2,42 \pm 0,78$ & $3,57 \pm 0,53$ & 3 & 4 & $-2,530$ & $0,011^{*}$ \\
\hline İlişkilendirme & $2,00 \pm 1,00$ & $3,00 \pm 0,00$ & 2 & 3 & $-1,890$ & 0,059 \\
\hline Saygı Duyma & $2,57 \pm 0,53$ & $3,71 \pm 0,48$ & 3 & 4 & $-2,530$ & $0,011^{*}$ \\
\hline Total & $46,42 \pm 12,75$ & $64,14 \pm 8,35$ & 38 & 67 & $-2,366$ & $0,018^{*}$ \\
\hline
\end{tabular}




\section{TARTIŞMA}

Engelli bireylerin tiyatro aktivitesine katılımlarının iletişim ve etkileşim becerileri üzerine etkilerinin incelendiği çalışmamızda, tiyatro aktivitesine katılım gösteren engelli bireylerin iletişim ve etkileşim becerilerinde anlamlı gelişmeler tespit edilmiştir.

Engelli gençler kendilerini toplumdan soyutlayıp pasif serbest zaman aktivitelerine yöneltmişlerdir (Çöl, 2015). Halbuki aktif serbest zaman aktivitelerine katıımının arkadaşık ilişkilerini, iletişim becerilerini, bağımsızlığı ve toplumsallık bilincini geliştirdiği belirtilmiştir (Barnes, Mercer ve Shakespeare, 1999; Dijkers, Whiteneck ve ElJaroudi, 2000; King, Imms, Palisano ve ark, 2013; Preskitt, Goldfarb, Mulvihill ve ark, 2013; Raab ve Dunst, 2005). Bu yüzden engellilerin çocuk yaşta özellikle ev dışında, diğer insanlarla etkileşim içinde olunan, becerileri geliştiren sosyal yönü olan ve yetenek gerektiren aktivitelere katılım düzeylerinin arttırılması gerekmektedir.

Catteral ve arkadaşlarının (1999) 8 ve 12. sınıflar arasındaki sağlıklı öğrencilerde tiyatro aktivitesine yoğun katılım göstermenin getirilerinin ortaya koyulduğu çalışmalarında sanat aktivitelerine katııım gösteren kişilerin kendini ifade etmede, iletişim becerilerinde, başkalarının fikirlerine saygı duymada ve grup üyeleriyle iş birliği yapabilme becerilerinde katıım göstermeyenlere göre pozitif yönde anlamlı farkları olduğu saptanmıştır (Catterall ve ark, 1999). Çalışmamızda tiyatro aktivitesine katılımdaki pozitif kazanımlar engelli bireyler üzerinde gösterilmiştir. Engellilerde temas, bakışlar, yönelmeler, postür, telaffuz, kendini savunma, etkileşimi başlatma, etkileşimi sürdürme, duygulanımını ifade etme, sesini ayarlama, kendini ifade etme, odaklanma ve saygı duyma becerilerinin tiyatro ile gelişmesi, sanatın her birey üzerindeki olumlu etkisini savunmaktadır.

Catteral ve arkadaşlarının (1999) yaptıkları çalışmada tiyatronun farklı gruplarda faydaları hakkında literatürde kanıt seviyesinin düşük olduğundan ve çok nadir çalışmalara rastlanıldığından bahsedilmiştir (Catterall ve ark, 1999). Tiyatro aktivitelerine katılımın az olmasından dolayı da bu konuda yapılan çalışmalar sınırlı kalmıştır.

Csikszentmihalyi'nin (1990) akış (flow) teorisini tanıttığı çalışmasında, bir aktivitede eylem için fırsatlar (zorlanmalar) ve eylemi gerçekleştirmek için kapasite (beceriler) uyum içerisinde olduğunda doğru öğrenme ve beceri kazanımının ortaya çıkacağından bahsedilmektedir. Yani kişinin katıım gösterdiği aktivite, kapasitesini aşmamalı aynı zamanda da becerilerini zorlamalıdır (Csikszentmihalyi, 1990). Çalışmamızda, 12 hafta süren, profesyonel bir tiyatro atölyesi desteği ile yürütülen hazırlık ve prova çalışmaları sonucunda, gerekli yerlerde destek sağlanarak, 7 katılımcımız yaklaşık 80 kişilik bir seyirci karşısında tam bir oyun oynamıştır. Böylelikle, katıımcıların kapasitesi aşılmadığı gibi becerileri zorlanmış ve doğru beceri kazanımı ortaya çıkartılmıştır.

Tiyatro, katııımcılar için ürün oluşturma odaklı bir üretici aktivite olmasının yanı sıra, onların iletişim etkileşim becerilerini artırıcı bir terapi aracı da olduğundan dolayı katıımcılar için hem anlamlı hem de amaca yönelik bir aktivitedir. Bu yönleriyle çalışmamız engelli bireylerde; Iletişim ve Etkileşim Becerileri Değerlendirmesi'ne göre iletişim ve etkileşimin becerilerinde anlamlı artışlar sağlarken, yukarıda açıklanan nedenlere bağı olarak bağımsız yaşam becerilerini de geliştiren bir yapıya sahiptir.

Çalışmamızın limitasyonları vardır; kontrol grubu bulunmamaktadır. Çalışmaya sadece 7 kişi dahil edilmiştir, bu sayının daha fazla olmasının sonuçların daha güvenilir olmasını sağlayabileceği düşünülmektedir. Çalışmamızda toplam 12 prova alınmış ve bir kez sahnede izleyicilerin karşısında oynanmıştır. Bu sayıların daha fazla olmasının iletişim etkileşim becerilerindeki gelişmelerin daha kalıcı olmasını sağlayabileceği düşünülmektedir.

Çalışmamızın kuvvetli yönleri vardır; değerlendirme aracı olarak tamamen gözleme dayalı olan İletişim ve Etkileşim Becerileri Değerlendirmesi kullanılmıştır. Literatürde tiyatro yapan kişilerin kendi kazandıkları becerilere yönelik görülerinin ve bakış açılarının dar olması nedeniyle yapılacak çalışmalarda güvenilir sonuçlar elde etmenin zor olacağından söz edilmiştir (Catterall ve ark, 1999). Çalışmamızda, tiyatro aktivitesine yoğun katııım gösteren (haftada $1 \mathrm{kez}$ ) engelli bireyler, kendilerinden bilgi alınmaksızın, doğrudan gözlem yoluyla değerlendirilmişlerdir. Böylelikle literatürde bahsedilen araştırma limitasyonlarının önüne 
geçilmesini sağlamıştır. Ancak, her ne kadar sadece gözleme dayalı bir değerlendirme olsa da Illetişim ve Etkileşim Becerileri Değerlendirmesi'nin alt başlıkları için Türkçe güvenirlik çalışması yapılması gerekebilir. Bu çalışmada öncesi ve sonrası değerlendirmenin aynı terapist tarafından yapılması yoluyla bu limitasyonun önüne geçilmiştir.

Çalışmamız, sonuçları ve katılımcılara sağladıkları açısından ergoterapi felsefesi ile doğrudan örtüşmektedir. Gelecekte bu konuda yapılacak çalışmalarda dahil edilecek olan bireylerin oyuna ve rollere kognitif ve fiziksel uygunluğunun değerlendirilmesi, uygunluk düzeyinin artırılması için yapılabilecek adaptasyon ve düzenlemelerin oluşturulması konularında ergoterapist desteğinden faydalanılabilir. Ayrıca katılımcılara kendi fiziksel ve kognitif kapasitelerine uygun olarak rol dağıtım sürecinde de ergoterapistler destek verebilir. Ayn şekilde gelecekte yapılacak çalışmalarda provalar ve hazırlık çalışmaları sırasında, katılımcıların hafıza (ezber yapma, hangi sırada çıkacağını hatırlama, ne zaman söze gireceğini hatırlama) ve dikkat (oyunu takip etme, kendi sırası geldiğinde fark etme, oyunda ters giden ya da yanlış yapılan yerleri fark ederek telafi etmeye hazırlanma) gibi becerilerine yönelik kognitif çalışmalar ve katılımcıların prova saatlerini takip etmesine, hazırlık çalışmaların yapılacağı yerleri kolayca bulabilmelerine yönelik yer-zaman oryantasyonu çalışmalarının yapılmasında ergoterapist desteğinin sağlanması etkili olabilir.

\section{Kaynaklar}

Barnes, C., Mercer, G., \& Shakespeare, T. (1999). Exploring disability: a sociological introduction. Cambridge: Polity Press, 182-210.

Catterall, J., Chapleau, R., \& Iwanga, J. (1999). Involvement in the arts and human development: General involvement and intensive involvement in music and theatre arts. In Champions of Change: The impact of the arts on learning . Washington DC: Arts Education Partnership.

Csikszentmihalyi, M. (1990). Flow. The Psychology of Optimal Experience. New York (HarperPerennial).

Çöl, G. (2015). Özel gereksinimi olan çocukların boş zaman aktivitelerine katılımını etkileyen faktörler. Hacettepe Üniversitesi. Sağlık Bilimleri Enstitüsü. Fizik Tedavi ve Rehabilitasyon Programı yayımlanmamış Yüksek Lisans Tezi. Ankara.

Dijkers, M. P., Whiteneck, G., \& El-Jaroudi, R. (2000). Measures of social outcomes in disability research. Arch
Phys Med Rehabil, 81, 63-80.

Forsyth, K., Kielhofner, G., Forsyth, K., Salamy, M., \& Simon, S. (1998). A User's Guide to the Assessment of Communication and Interaction Skills (ACIS). University of Chicago.

Forsyth, K., Lai, J. S., \& Kielhofner, G. (1999). The assessment of communication and interaction skills (ACIS): Measurement properties. Br J Occup Ther, 62(2), 69-74.

Hughes, J., \& Wilson, K. (2004). Playing a part: the impact of youth theatre on young people's personal and social development. Res Drama Educ, 9(1), 57-72

Johnston, K. (2012). Stage Turns: Canadian Disability Theatre. Montreal: McGill Queens University Press.

King, G., Imms, C., Palisano, R., Majnemer, A., Chiarello, L., Orlin, M., \& Avery, L. (2013). Geographical patterns in the recreation and leisure participation of children and youth with cerebral palsy: A CAPE international collaborative network study. Dev Neurorehabil, 16(3), 196-206.

Lexén, A., \& Bejerholm, U. (2016). Exploring communication and interaction skills at work among participants in individual placement and support. Scand J Occup Ther, 23(4), 314-319.

Perry, M. M. R. (2003). Relating improvisational music therapy with severely and multiply disabled children to communication development. J Music Ther, 40(3), 227246.

Preskitt, J. K., Goldfarb, S. S., Mulvihill, B. A., Colburn, S., \& Davis, M. M. (2013). Future plans and social/recreational activities of youth with special health care needs: the implications of parental help in completing surveys. Disabil Health J, 6(4), 343-35.

Raab, M., \& Dunst, C. J. (2005). Interest-based child participation in everyday learning activities. CASEinPoint, 1(2), 1-5.

Sandahl, C. (2005). From the Streets to the Stage: Disability and the Performing Arts. PMLA, 120(2), 620-624.

Simon, S. (1989). The development of an assessment for communication and interaction skiffs. (Unpublished Master's thesis). Chicago, II: Universityof Illinois at Chicago. 
Ek-1. Illetişim ve Etkileşim Değerlendirmesi Alanları ve Terimleri

\section{Fiziksellik}

- Temas: Diğerleriyle fiziksel temas kurar.

- Bakış: Diğerleriyle iletişim ve etkileşim kurmak için bakışlarını kullanır.

- Jestler: Sözlü mesajı nitelendirmek, vurgulamak ve/veya tamamlamak için sözlü olmayan iletişimin kullanımı, yanlış kullanımı veya yokluğunu ifade eder.Bir şeyi belirtmek, örnek göstermek veya vurgulamak için vücut hareketlerini kullanır.

- Manevralar: Vücutlarını diğer kişilerin vücutlarıyla ilişkili olarak hareket ettirir.

- Yönelmeler: Vücutlarını diğer kişilerin vücutlarıyla ya da occupational form ile ilişkili olarak yönlendirir.

- Postür: Fiziksel pozisyonunu tayin eder.

\section{Bilgi Alış-Verişi}

- Telaffuz: Temiz ve anlaşılır bir konuşma kullanır.

- Kendini Savunma: Kendi arzularını, kabul etmediği şeyleri ve isteklerini direk olarak ifade eder.

- Soru Sorma: Gerçeklere dayalı ve kişisel bilgiler talep eder.

- Etkileşimi Başlatmak: Etkileşimi başlatır.

- Doğru İfade Etmek: Kendi duygulanımını ve davranışlarını sergiler.

- Modüle Etmek: Konuşma sırasında ses tonunu ayarlar.

- Paylaşmak: Gerçeklere dayalı ve kişisel bilgiler verir.

- Kendini İfade Etmek: Kelimeler, ifadeler ve cümleler kullanarak kendini anlaşııır kılar.

- Sürdürmek: Uygun bir süre boyunca konuşmayı sürdürür.

\section{İlişkiler}

- İşbirliği Yapma: Ortak bir son hedefe ulaşmak amacıyla eylemlerini diğer kişilerle koordine eder.

- Uyumlu Olma: Örtülü ve açık sosyal normlara uyar.

- Odaklanma: Konuşmayı ve davranışı süregelen sosyal eyleme yönlendirir.

- Illişkilendirme: Diğerleriyle bir yakınlık sağlamaya yönelik davranış tarzı benimser.

- Saygı Duyma: Diğer kişilerin istek ve tepkilerine uyum sağlar. 
